\title{
A Combined Ion Implantation/Nanosecond Laser Irradiation Approach towards Si Nanostructures Doping
}

\author{
F. Ruffino, ${ }^{1,2}$ L. Romano, ${ }^{1,2}$ E. Carria,,${ }^{1,2}$ M. Miritello, ${ }^{2}$ M. G. Grimaldi, ${ }^{1,2}$ \\ V. Privitera, ${ }^{2,3}$ and F. Marabelli ${ }^{4}$ \\ ${ }^{1}$ Dipartimento di Fisica e Astronomia, Università di Catania, via S. Sofia 64, 95123 Catania, Italy \\ ${ }^{2}$ MATIS, CNR, IMM, via S. Sofia 64, 95123 Catania, Italy \\ ${ }^{3}$ Istituto per la Microelettronica e Microsistemi (CNR)-(IMM)—Consiglio Nazionale delle Ricerche VIII Strada 5, \\ 95121 Catania, Italy \\ ${ }^{4}$ Dipartimento di Fisica “A.Volta," Università degli Studi di Pavia, via Bassi 6, 27100 Pavia, Italy
}

Correspondence should be addressed to F. Ruffino, francesco.ruffino@ct.infn.it

Received 28 September 2011; Accepted 23 November 2011

Academic Editor: Arturo I. Martinez

Copyright () 2012 F. Ruffino et al. This is an open access article distributed under the Creative Commons Attribution License, which permits unrestricted use, distribution, and reproduction in any medium, provided the original work is properly cited.

\begin{abstract}
The exploitation of Si nanostructures for electronic and optoelectronic devices depends on their electronic doping. We investigate a methodology for As doping of Si nanostructures taking advantages of ion beam implantation and nanosecond laser irradiation melting dynamics. We illustrate the behaviour of As when it is confined, by the implantation technique, in a $\mathrm{SiO}_{2} / \mathrm{Si} / \mathrm{SiO}_{2} \mathrm{multilayer}$ and its spatial redistribution after annealing processes. As accumulation at the $\mathrm{Si} / \mathrm{SiO}_{2}$ interfaces was observed by Rutherford backscattering spectrometry in agreement with a model that assumes a traps distribution in the Si in the first $2-3 \mathrm{~nm}$ above the $\mathrm{SiO}_{2} / \mathrm{Si}$ interfaces. A concentration of $10^{14}$ traps $/ \mathrm{cm}^{2}$ has been evaluated. This result opens perspectives for As doping of $\mathrm{Si}$ nanoclusters embedded in $\mathrm{SiO}_{2}$ since a $\mathrm{Si}$ nanocluster of radius $1 \mathrm{~nm}$ embedded in $\mathrm{SiO}_{2}$ should trap 13 As atoms at the interface. In order to promote the As incorporation in the nanoclusters for an effective doping, an approach based on ion implantation and nanosecond laser irradiation was investigated. Si nanoclusters were produced in $\mathrm{SiO}_{2}$ layer. After As ion implantation and nanosecond laser irradiation, spectroscopic ellipsometry measurements show nanoclusters optical properties consistent with their effective doping.
\end{abstract}

\section{Introduction}

The future exploitation of semiconductor nanostructures $(\mathrm{Si}$ nanostructures in particular) depends on the understanding and control of their electronic doping. Doping of semiconductor nanostructures has proven to be distinct from the corresponding bulk materials [1-5] and recently great attention has been focused on developing practical methodologies to dope and control the doping properties of Si nanostructures such, as nanoclusters (NCs) [6-13] and nanowires [14-17], and on developing theoretical approaches to understand these properties [18-23]. The control of doping properties of $\mathrm{Si}$ nanostructures allows the fabrication of complex nanomaterials characterized by unpreceded electrical and optoelectronic functionalities.
In this work, we present a novel approach, based on ion implantation and nanosecond laser irradiations, to dope Si-based low-dimensional systems by As. In particular, two different types of Si low-dimensional systems are investigated relatively to their As-doping properties: a nanoscale Si layer embedded between two $\mathrm{SiO}_{2}$ layers and $\mathrm{Si}$ NCs embedded in $\mathrm{SiO}_{2}$. Concerning the former case, we illustrate the behaviour of As confined, by the implantation technique, in a $\mathrm{SiO}_{2}(70 \mathrm{~nm}) / \mathrm{Si}(30 \mathrm{~nm}) / \mathrm{SiO}_{2}(70 \mathrm{~nm})$ multilayer and its spatial redistribution when conventional annealing processes are performed. Concerning the latter experiment, after the As implantation in the $\mathrm{SiO}_{2}$ layer containing Si NCs, laser irradiation was used to melt the Si NCs and to promote the As atomic incorporation in the Si NCs in order to achieve high doping level. Spectroscopic ellipsometry was 


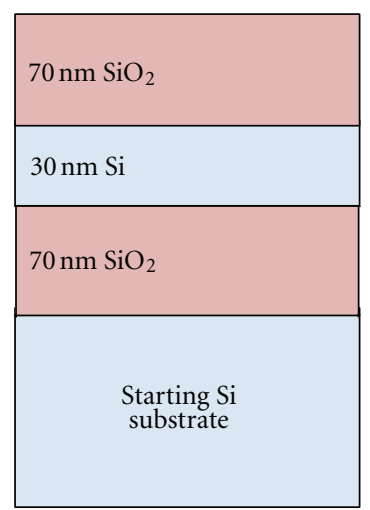

(a) nanoscale multilayers

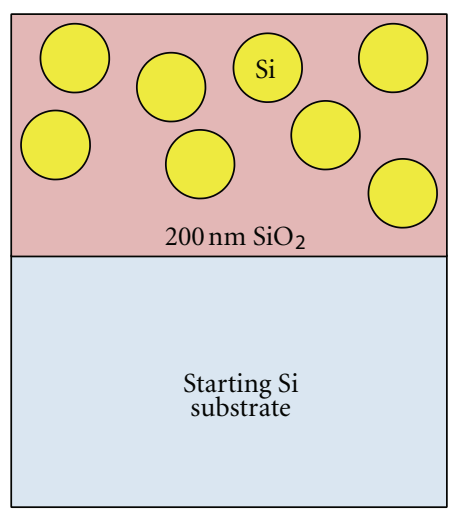

(b) $\mathrm{Si} \mathrm{NCs}$ embedded in $\mathrm{SiO}_{2}$

Figure 1: Scheme of the fabricated samples.

performed to investigate the effective As doping of the Si NCs.

\section{Experimental}

\subsection{Samples Preparations}

2.1.1. Nanoscale $\mathrm{SiO}_{2} / \mathrm{Si} / \mathrm{SiO}_{2}$ Multilayer. The nanoscale multilayers were fabricated by sequential sputtering depositions of $\mathrm{Si}$ and $\mathrm{SiO}_{2}$ using an AJA RF magnetron sputtering apparatus (Ar plasma, $5 \times 10^{-3}$ mbar pressure during the depositions). A multilayer $\mathrm{SiO}_{2}(70 \mathrm{~nm}) / \mathrm{Si}(30 \mathrm{~nm}) / \mathrm{SiO}_{2}$ $(70 \mathrm{~nm})$ was grown on crystalline $\mathrm{Si}(\mathrm{c}-\mathrm{Si})$, as shown in the scheme of Figure 1(a). During the depositions, the c-Si substrate was heated at $400^{\circ} \mathrm{C}$. Then, two consecutive As implants, the first at $50 \mathrm{keV}$ and the second one at $130 \mathrm{keV}$ (at room temperature), were performed on such a sample. In this way, an As box profile centered in the Si layer, as suggested by TRIM simulations [24], was obtained. Three different total As fluences were realized: $2.5 \times 10^{15}, 5 \times 10^{15}$, and $1 \times 10^{16} \mathrm{As} / \mathrm{cm}^{2}$. After ion implantation, the samples were annealed by using a standard Carbolite horizontal furnace in dry $\mathrm{N}_{2}$.

2.1.2. Si Nanoclusters in $\mathrm{SiO}_{2}$. Si NCs were produced in a $\mathrm{SiO}_{2}$ matrix following a standard procedure described in the literature $[25,26] ; 200 \mathrm{~nm}$ thick substoichiometric $\mathrm{SiO}_{x}$ (the $\mathrm{Si}$ excess is $6.3 \%$ atomic) was sputter-deposited (using the AJA RF magnetron sputtering apparatus) on cSi substrate a. After a $1100^{\circ} \mathrm{C}$-60-minute annealing (in dry $\mathrm{N}_{2}$ ) a clustering process of the exceeding $\mathrm{Si}$ occurs. The net result is the formation of Si NCs of radius $r \sim 1.8 \mathrm{~nm}$, surface-to-surface distance of $d \sim 10 \mathrm{~nm}$ and density $N \sim$ $9 \times 10^{17} \mathrm{~cm}^{-3}$ embedded in $\mathrm{SiO}_{2}$ (a scheme is presented in Figure 1(b)). $120 \mathrm{keV}$ As implants with a fluence of $5 \times$ $10^{15} \mathrm{As} / \mathrm{cm}^{2}$ were performed in order to obtain an As box profile in the $\mathrm{SiO}_{2}$ layer. After ion implantation, the samples were processed by laser annealing. Laser irradiations were performed by a pulsed ( $10 \mathrm{~ns}) \mathrm{Nd}$ :yttrium aluminum garnet
YAG laser operating at $532 \mathrm{~nm}$ (Quanta-ray PRO-Series pulsed Nd:YAG laser).

2.2. Characterizations. Rutherford backscattering analyses (RBS) were performed using a $2 \mathrm{MeV}^{4} \mathrm{He}^{+}$beam in normal incidence with a scattering angle of $165^{\circ}$ and in glancing angle configuration (tilt angle of $64^{\circ}$ ) in order to improve the depth resolution. The RBS spectra were analyzed by the RUMP code [27].

Spectroscopic ellipsometry was performed in the $0.2-$ $1 \mu \mathrm{m}$ wavelength range in order to study the optical response of the samples. In particular, an effective medium approximation simulation analysis has been applied to the ellipsometric data in order to obtain both real $\left(\varepsilon_{1}\right)$ and imaginary $\left(\varepsilon_{2}\right)$ parts of the dielectric function [28-30].

Spreading resistance profiling (SRP) was performed in order to evaluate the dopant electrical activation after the annealing [31].

\section{Results and Discussions}

Figure 2 (a) reports the As concentration profile of the As-implanted $\left(5 \times 10^{15} \mathrm{As} / \mathrm{cm}^{2}\right)$ multilayer sample before (full line) and after (line with circles) annealing $\left(950^{\circ} \mathrm{C}\right.$ for $80 \mathrm{~min}$ ). We can observe that before annealing, the maximum As concentration in the $\mathrm{Si}$ thin layer is about $5.6 \times 10^{20}$ atoms $/ \mathrm{cm}^{3}$. After annealing the As concentration in the Si layer decreases at a minimum of about $4.1 \times$ $10^{20}$ atoms $/ \mathrm{cm}^{3}$. The As diffuses through the Si layer towards the two $\mathrm{Si} / \mathrm{SiO}_{2}$ interfaces (indicated by the two dashed lines) where it is accumulated up to a maximum concentration of about $6.4 \times 10^{20}$ atoms $/ \mathrm{cm}^{3}$. Because of the very low diffusion coefficient of As in $\mathrm{SiO}_{2}$ at $950^{\circ} \mathrm{C}$, the As profile concentrations remain unchanged in the $\mathrm{SiO}_{2}$ layers during annealing. The diffusion coefficient of $\mathrm{As}$ in $\mathrm{Si}$ at $950^{\circ} \mathrm{C}$ is much higher than in $\mathrm{SiO}_{2}$ : about $2 \times 10^{-14} \mathrm{~cm}^{2} / \mathrm{s}$ in $\mathrm{Si}$ [32] (corresponding, after $80 \mathrm{~min}$., to a diffusion length of $98 \mathrm{~nm}$ ) and about $3 \times 10^{-18} \mathrm{~cm}^{2} / \mathrm{s}$ in $\mathrm{SiO}_{2}$ [33] (corresponding, after $80 \mathrm{~min}$., to a diffusion length of $1.2 \mathrm{~nm}$ ). The diffusion of As is hence inhibited in $\mathrm{SiO}_{2}$ with respect to Si. Figure 2(b) 


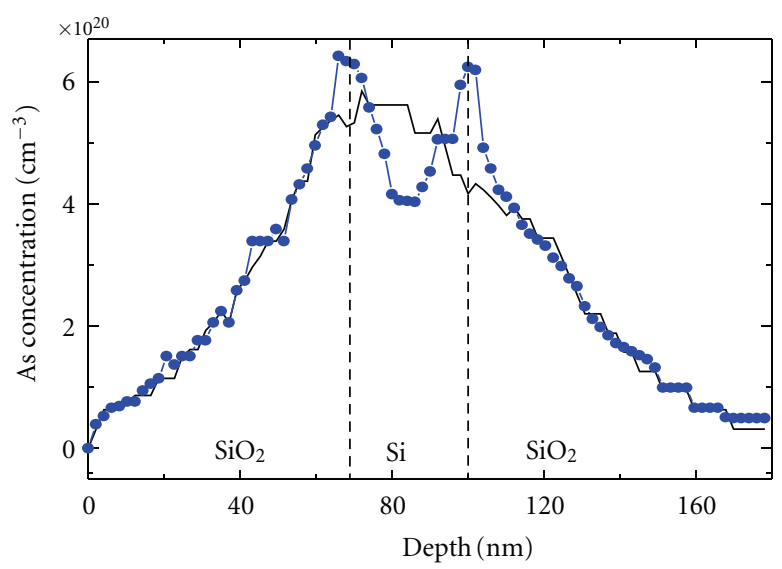

- As implanted

-•- As-implanted $+950^{\circ} \mathrm{C} 80 \mathrm{~min}$

(a)

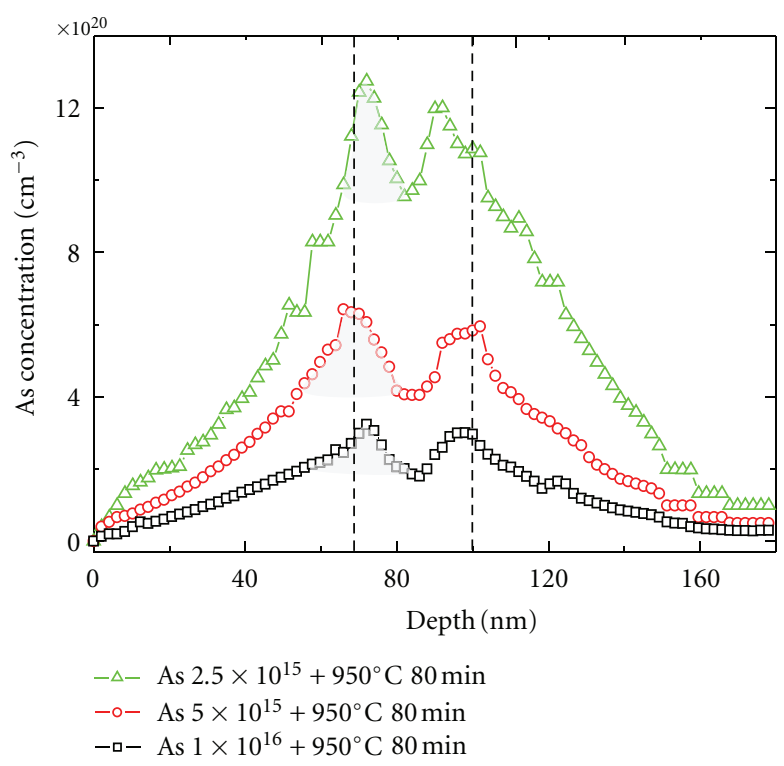

(b)

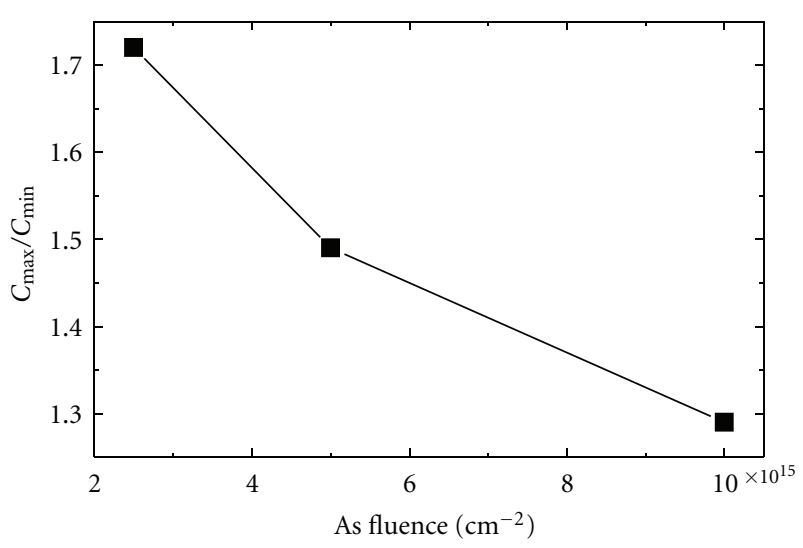

(c)

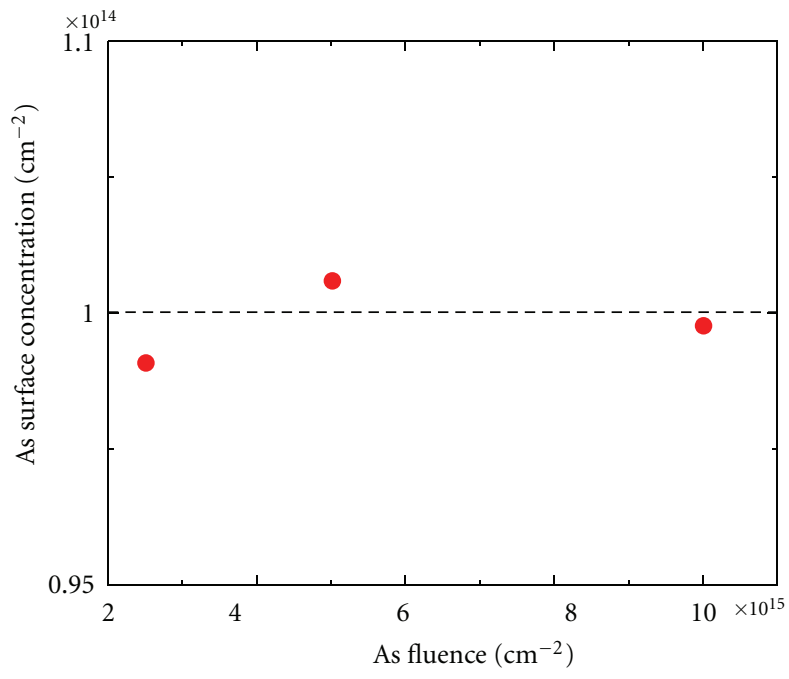

(d)

Figure 2: (a) As concentration profile in the nanoscale multilayer implanted with As fluence of $5 \times 10^{15}$ As/ $\mathrm{cm}^{2}$ before (full line) and after (line with circles) the $950^{\circ} \mathrm{C} 80 \mathrm{~min}$ annealing process; the dashed lines represent the $\mathrm{Si} / \mathrm{SiO}_{2}$ interfaces. (b) As concentration profiles for the nanoscale multilayers implanted with As fluence of $2.5 \times 10^{15}, 5 \times 10^{15}$, and $1 \times 10^{16} \mathrm{As} / \mathrm{cm}^{2}$ after the $950^{\circ} \mathrm{C} 80$ min annealing process; the dashed lines represent the $\mathrm{Si} / \mathrm{SiO}_{2}$ interfaces. (c) "effective segregation coefficient" $C_{\max } / C_{\min }$, calculated as the ration of maximum As concentration at the $\mathrm{Si} / \mathrm{SiO}_{2}$ interfaces and the minimum As concentration at the center of the Si layer, versus the As fluence. (d) Estimated values of the amount of As surface concentration trapped at each $\mathrm{Si} / \mathrm{SiO}_{2}$ interface as a function of the As-implanted fluence.

reports the As concentration profile of the three samples implanted with As fluencies of $2.5 \times 10^{15}, 5 \times 10^{15}$ and $1 \times 10^{16} \mathrm{As} / \mathrm{cm}^{2}$ after annealing. The As depletion in the $\mathrm{Si}$ layer and the As accumulation at the $\mathrm{Si} / \mathrm{SiO}_{2}$ interfaces (represented by dashed line in Figures 2(a) and 2(b)) occurs for all the samples. We calculated an "effective segregation coefficient" $C_{\max } / C_{\min }$, for each sample, as the ratio between the maximum As concentration at the $\mathrm{Si} / \mathrm{SiO}_{2}$ interfaces and the minimum As concentration at the center of the Si layer. This coefficient is reported in Figure 2(c) as a function of the implanted fluence, and it quantifies the efficiency of the As accumulation at the $\mathrm{Si} / \mathrm{SiO}_{2}$ interfaces. The As accumulation process decreases its efficiency with increasing the implanted As fluence.

Several diffusion models have been proposed to describe the As redistribution in $\mathrm{Si} / \mathrm{SiO}_{2}$ systems during postimplantation annealing [34-38]. In these models, particular emphasis is devoted to consider the effects of the As-vacancy complexes on diffusion and/or electrical deactivation, but they do not predict the dopant accumulation near the surface $[35,37]$. Ferri et al. [38] implanted As with energies between $1-10 \mathrm{keV}$ both in samples with only the native oxide and in sample with a layer of $11 \mathrm{~nm}$ of grown oxide. Then, they annealed the specimens in $\mathrm{N}_{2}$ atmosphere at temperatures 


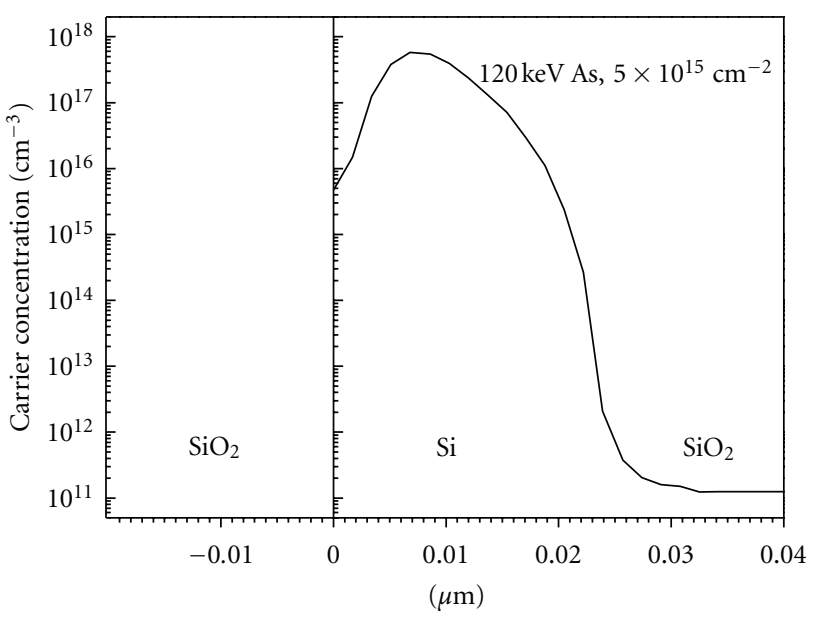

FIGURE 3: SRP carrier concentration in the nanoscale multilayer implanted with As fluence of $5 \times 10^{15} \mathrm{As} / \mathrm{cm}^{2}$.

between 800 and $1025^{\circ} \mathrm{C}$ for different times between $5 \mathrm{~s}$ and $4 \mathrm{~h}$. They determined the As distribution in proximity of the samples surface by using secondary ion mass spectrometry and Z-contrast scanning transmission electron microscopy. In particular, an As pileup in the first nanometers of the $\mathrm{Si}$ matrix in proximity of the $\mathrm{SiO}_{2} / \mathrm{Si}$ interface was observed. The phenomenon was explained with a "Fickian" standard diffusion by assuming the presence of "dopant traps" near the $\mathrm{SiO}_{2} / \mathrm{Si}$ interface that cause a reduction of the dopant able to diffuse inside the bulk. Their results support the hypothesis that the As accumulation in proximity of the surface is due to a dopant trapping in energetically favourite places. Their simulations routine considers unpaired point defects and dopant-defect pairs as mobile species and the unpaired dopant on lattice sites as immobile species. A dopant atom cannot diffuse on its own; it needs the presence of a point defect (a silicon self-interstitial or a lattice vacancy in different charge states) in the near neighborhood as a diffusion vehicle. Introducing such a "traps" distribution into the $\mathrm{Si}$ in the first $2-3 \mathrm{~nm}$ above the $\mathrm{SiO}_{2} / \mathrm{Si}$ interface, they obtained good agreements between simulation and measured profiles. Furthermore, their results demonstrate that the trapping behaviour of the region near the surface is not due to defects or impurities introduced by the implantation, but it is a property induced by the surface. On the basis of such a model, we could speculate that, in our samples, the accumulation of As at the two $\mathrm{Si} / \mathrm{SiO}_{2}$ interfaces is due to the formation of As-Si point defect pairs that diffuse through the $\mathrm{Si}$ towards the $\mathrm{Si} / \mathrm{SiO}_{2}$ interfaces where they are trapped (and accumulated) in energetically favourite places. Furthermore, the concentration of the traps at the $\mathrm{Si} / \mathrm{SiO}_{2}$ interface is an intrinsic characteristic of the interfacet and it has been estimated to be about $10^{14}$ traps $/ \mathrm{cm}^{2}$ by measuring the area of the As peaks in Figure 2(b) (grey areas), as summarized in Figure 2(d). This qualitatively explains the decrease of $C_{\max } / C_{\min }$ for increasing the As fluence. In fact, the number of As atoms accumulated at the $\mathrm{Si} / \mathrm{SiO}_{2}$ interfaces is the same for all the samples independently on the As-implanted fluence; in the sample implanted with
$2.5 \times 10^{15} \mathrm{As} / \mathrm{cm}^{2}$, only the $4 \%$ of the total implanted As is accumulated at the interfaces, at this percentage decreases at $2 \%$ and $1 \%$ for the samples implanted with $5 \times 10^{15} \mathrm{As} / \mathrm{cm}^{2}$ and $10^{16} \mathrm{As} / \mathrm{cm}^{2}$, respectively.

Finally, on these nanoscale multilayers samples, SPR measurements were performed to evaluate the carrier concentration profiles. Figure 3 shows the measured carriers concentration in the multilayer sample implanted by $5 \times$ $10^{15} \mathrm{As} / \mathrm{cm}^{2}$ after annealing $\left(950^{\circ} \mathrm{C} 80 \mathrm{~min}\right)$. The maximum carriers concentration in the Si layer is about $10^{18} \mathrm{~cm}^{-3}$, indicating $\sim 1 \%$ of dopant activation after annealing.

The result concerning the surface concentration of As atoms $\left(10^{14} \mathrm{~cm}^{-2}\right)$ trapped at the interfaces of the $\mathrm{SiO}_{2} / \mathrm{Si} / \mathrm{SiO}_{2}$ multilayer can be used to infer a crucial characteristic of the doping properties of Si NCs using ion beam techniques. Si NCs embedded in $\mathrm{SiO}_{2}$ are widely investigated for their novel size-dependent electronic and optoelectronic properties [6-13]. In particular, the exploitation of the properties of such systems in real devices demands an accurate control of their doping. On the basis of the previous results, we can conclude that if we consider a Si NCs embedded in $\mathrm{SiO}_{2}$ characterized by a radius of $1.8 \mathrm{~nm}$, after As implant and annealing about 40 As atoms are trapped at the $\mathrm{Si} / \mathrm{SiO}_{2}$ interface. For a NCs density of $9 \times 10^{17} \mathrm{~cm}^{-3}$, an As concentration of $3.6 \times 10^{19} \mathrm{As} / \mathrm{cm}^{3}$ is trapped. This fact involves the implantation of As concentrations higher than $3.6 \times 10^{19} \mathrm{As} / \mathrm{cm}^{3}$ in order to have the chance that at least an As atom can be incorporated in a Si NCs for an effective doping. Alternatively to conventional annealing processes, we explored a laser annealing process in order to promote such a high As concentration doping of Si NCs. In particular, the idea was to use a nanosecond laser irradiation to melt the Si NCs so to promote the As atoms incorporation in the liquid Si NCs. In order to exploit this idea, the following experiment was performed: $200 \mathrm{~nm}$ thick substoichiometric $\mathrm{SiO}_{x}$ (Si excess of $6.3 \mathrm{at} \%$ ) was sputter-deposited on c-Si substrate. After a $1100^{\circ} \mathrm{C}-60$ minutes annealing (in dry $\mathrm{N}_{2}$ ) a clustering process of the exceeding Si occurs. The net result is the formation of Si NCs of radius $r \sim 1.8 \mathrm{~nm}$, surface-tosurface distance of $d \sim 10 \mathrm{~nm}$, and density $N \sim 9 \times 10^{17} \mathrm{~cm}^{-3}$ embedded in $\mathrm{SiO}_{2}[25,26]$. Then, a $120 \mathrm{keV}$ As ion implant, at $5 \times 10^{15} \mathrm{As} / \mathrm{cm}^{2}$, was performed to obtain As box profile in the $\mathrm{SiO}_{2}$ layer. Finally, a single pulse laser irradiation process at $407 \mathrm{~mJ} / \mathrm{cm}^{2}$, by a pulsed (10 ns) Nd:yttrium aluminum garnet YAG laser operating at $532 \mathrm{~nm}$, was performed. Spectroscopic ellipsometry allowed us to evaluate the laser effect on the optical constants of the Si NCs without and with the presence of the As. Figure 4 reports the measured optical constants $\varepsilon_{1}$ (real part of the dielectric constant, related to the reflection coefficient) and $\varepsilon_{2}$ (imaginary part of the dielectric constant, related to the extinction coefficient). In particular, Figure 4(a) reports the optical constants measured for the system $\mathrm{Si} \mathrm{NCs} / \mathrm{SiO}_{2}$, without As, after the $407 \mathrm{~mJ} / \mathrm{cm}^{2}$ laser irradiation. $\varepsilon_{1}$ and $\varepsilon_{2}$ are showed as a function of the wavelength of the incident radiation in the $0.2-1 \mu \mathrm{m}$ range, and the spectra of bulk $\mathrm{Si}$ are also reported for comparison (with the characteristic threshold at about $0.38 \mu \mathrm{m}$ for $\varepsilon_{1}$ and at about $0.29 \mu \mathrm{m}$ for $\varepsilon_{2}$ ). The notable feature is a reduction of the optical constants of Si NCs with respect to the bulk 


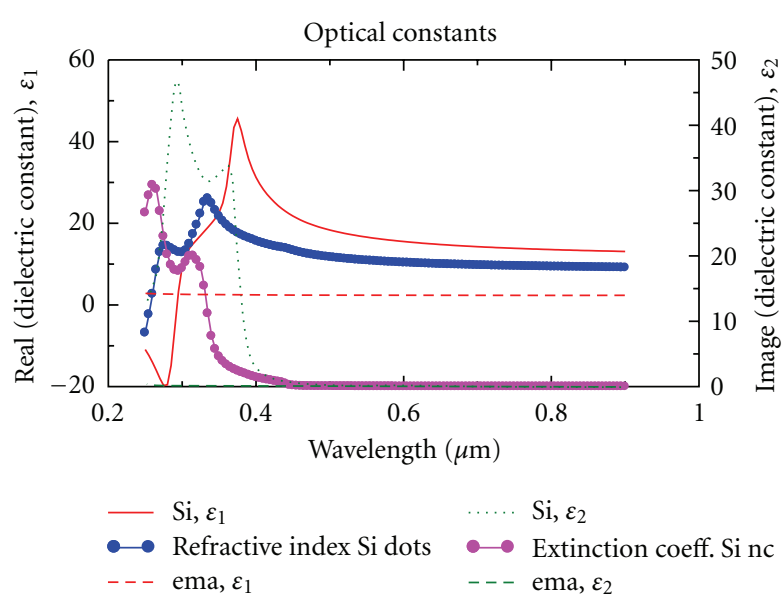

(a) $\varepsilon_{1}$ and $\varepsilon_{2}$ for bulk $\mathrm{Si}$ and $\mathrm{Si}$ NCs embedded in $\mathrm{SiO}_{2}$ after a $407 \mathrm{~mJ} / \mathrm{cm}^{2}$ laser irradiation

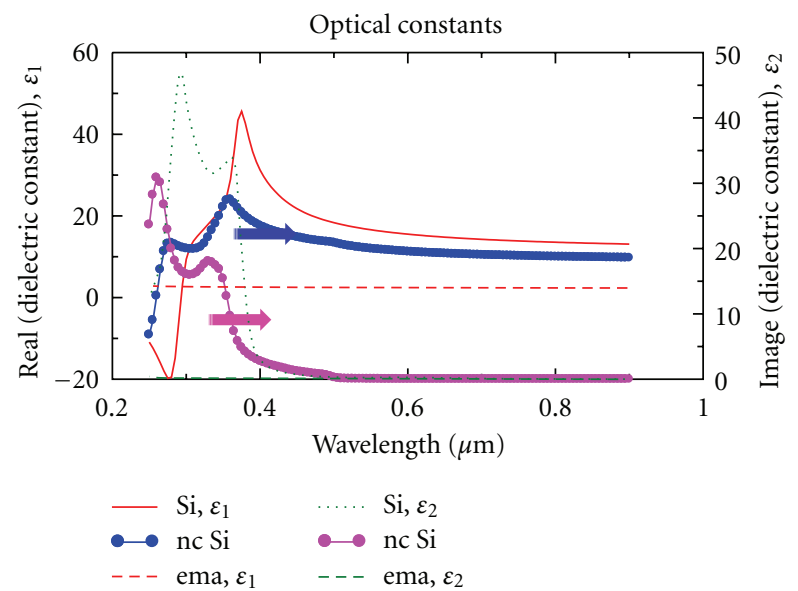

(b) $\varepsilon_{1}$ and $\varepsilon_{2}$ for bulk $\mathrm{Si}$ and $\mathrm{Si}$ NCs embedded in $\mathrm{SiO}_{2}$ after $5 \times 10^{15} \mathrm{As} / \mathrm{cm}^{2}$ ion implantation followed by a $407 \mathrm{~mJ} / \mathrm{cm}^{2}$ laser irradiation

FIGURE 4: Optical constants $\varepsilon_{1}$ (real part of the dielectric constant, related to the reflection coefficient) and $\varepsilon_{2}$ (imaginary part of the dielectric constant, related to the extinction coefficient) measured by the spectroscopic ellipsometry.

Si. This reduction is characteristic of the Si NCs due to their reduced dimensionality, as already shown in the literature $[29,30]$. In general, it has been well established that a reduction of the dielectric constants becomes significant as the size of the quantum confined physical systems, such as quantum dots and wires, approaches the nanometric range $[29,30,39,40]$. However, the origin of the reduction in the dielectric constant with the size is still not fully understood. It is often attributed to the opening of the gap, which should lower the polarizability. Figure 4(b) reports the optical constants measured for the system $\mathrm{Si} \mathrm{NCs} / \mathrm{SiO}_{2}$, after As implantation and after the $407 \mathrm{~mJ} / \mathrm{cm}^{2}$ laser irradiation. In this case, the notable feature is a shift of the peak of $\varepsilon_{1}$ of the NCs from $0.34 \mu \mathrm{m}$ to $0.36 \mu \mathrm{m}$ and a shift of the peak of $\varepsilon_{2}$ of the NCs from $0.32 \mu \mathrm{m}$ to $0.34 \mu \mathrm{m}$. These wavelength shifts of $\varepsilon_{1}$ and $\varepsilon_{2}$ are a clear signature of the effective doping of the Si NCs and, to our knowledge, are the first observation of a similar effects in Si NCs. Instead, similar shifts were previously observed for the peak of $\varepsilon_{1}$ and $\varepsilon_{2}$ of bulk Si when heavily doped by n-type dopants such as $\mathrm{P}$ and As followed by pulsed-laser annealing [28]. This red-shift phenomenon in the optical constants of the Si NCs, in the presence of the As and after the laser irradiation process, is a signature of the effective doping of the NCs by As atoms since it is consistent with the introduction of localized states in the NCs bandgap. These localized states decrease the energy of absorbed or emitted photons, increasing, as a consequence, their wavelength.

\section{Conclusion}

As redistribution in a $\mathrm{SiO}_{2}(70 \mathrm{~nm}) / \mathrm{Si}(30 \mathrm{~nm}) / \mathrm{SiO}_{2}(70 \mathrm{~nm})$ multilayer during postimplantation annealing produces an As accumulation at the $\mathrm{Si} / \mathrm{SiO}_{2}$ interfaces. Such an effect is qualitatively in agreement with a model that assumes a "traps" distribution into the $\mathrm{Si}$ in the first $2-3 \mathrm{~nm}$ above the
$\mathrm{SiO}_{2} / \mathrm{Si}$ interfaces. In particular, the traps concentration at the $\mathrm{Si} / \mathrm{SiO}_{2}$ interfaces was estimated in $10^{14}$ traps $/ \mathrm{cm}^{2}$. This opens perspectives in the As doping of Si NCs embedded in $\mathrm{SiO}_{2}$. For example, a $\mathrm{Si} \mathrm{NC}$ of radius $1.8 \mathrm{~nm}$ embedded in $\mathrm{SiO}_{2}$ should trap $40 \mathrm{As}$ atoms at the interface. Therefore, to promote the As atoms incorporation in the NCs for an effective doping, a combined approach based on ion implantation and nanosecond laser irradiation was investigated. Si NCs, of radius of $1.8 \mathrm{~nm}$ and density of $9 \times 10^{17} \mathrm{~cm}^{-3}$, were produced in a $200 \mathrm{~nm}$ thick $\mathrm{SiO}_{2}$ layer. After As ion implantation at fluence of $5 \times 10^{15} \mathrm{As} / \mathrm{cm}^{2}$ and $407 \mathrm{~mJ} / \mathrm{cm}^{2}$ nanosecond laser irradiation, spectroscopic ellipsometry showed optical properties of the NCs consistent with their effective doping. These results indicate that such a doping approach deserves further investigations in order to develop a better control of the doping process of a wide-range class of Si-based nanostructures.

\section{Acknowledgment}

The authors thank M. Italia of CNR-IMM for expert assistance with the SRP measurements.

\section{References}

[1] D. J. Norris, N. Yao, F. T. Charnock, and T. A. Kennedy, "Highquality manganese-doped ZnSe nanocrystals," Nano Letters, vol. 1, no. 1, pp. 3-7, 2001.

[2] M. Shim, C. Wang, D. J. Norris, and P. Guyot-Sionnest, "Doping and charging in colloidal semiconductor nanocrystals," MRS Bulletin, vol. 26, no. 12, pp. 1005-1008, 2001.

[3] S. B. Orlinskii, J. Schmidt, P. G. Baranov, D. M. Hofmann, C. De Mello Donegá, and A. Meijerink, "Probing the wave function of shallow $\mathrm{Li}$ and $\mathrm{Na}$ donors in $\mathrm{ZnO}$ nanoparticles," Physical Review Letters, vol. 92, no. 4, pp. 476031-476034, 2004. 
[4] S. C. Erwin, L. Zu, M. I. Haftel, A. L. Efros, T. A. Kennedy, and D. J. Norris, "Doping semiconductor nanocrystals," Nature, vol. 436, no. 7047, pp. 91-94, 2005.

[5] G. M. Dalpian and J. R. Chelikowsky, "Self-purification in semiconductor nanocrystals," Physical Review Letters, vol. 96, no. 22, Article ID 226802, 2006.

[6] M. Fujii, S. Hayashi, and K. Yamamoto, "Photoluminescence from B-doped Si nanocrystals," Journal of Applied Physics, vol. 83, no. 12, pp. 7953-7957, 1998.

[7] A. Mimura, M. Fujii, S. Hayashi, D. Kovalev, and F. Koch, "Photoluminescence and free-electron absorption in heavily phosphorus-doped Si nanocrystals," Physical Review B, vol. 62, no. 19 , pp. 12625-12627, 2000.

[8] M. Fujii, A. Mimura, S. Hayashi, Y. Yamamoto, and K. Murakami, "Hyperfine structure of the electron spin resonance of phosphorus-doped Si nanocrystals," Physical Review Letters, vol. 89, no. 20, pp. 2068051-2068054, 2002.

[9] M. Fujii, K. Toshikiyo, Y. Takase, Y. Yamaguchi, and S. Hayashi, "Below bulk-band-gap photoluminescence at room temperature from heavily P- and B-doped Si nanocrystals," Journal of Applied Physics, vol. 94, no. 3, pp. 1990-1995, 2003.

[10] A. R. Stegner, R. N. Pereira, K. Klein, H. Wiggers, M. S. Brandt, and M. Stutzmann, "Phosphorus doping of Si nanocrystals: interface defects and charge compensation," Physica B, vol. 401-402, pp. 541-545, 2007.

[11] R. Lechner, A. R. Stegner, R. N. Pereira et al., "Electronic properties of doped silicon nanocrystal films," Journal of Applied Physics, vol. 104, no. 5, Article ID 053701, 2008.

[12] A. R. Stegner, R. N. Pereira, K. Klein et al., "Electronic transport in phosphorus-doped silicon nanocrystal networks," Physical Review Letters, vol. 100, no. 2, Article ID 026803, 2008.

[13] M. Perego, C. Bonafos, and M. Fanciulli, "Phosphorus doping of ultra-small silicon nanocrystals," Nanotechnology, vol. 21, no. 2, Article ID 025602, 2010.

[14] Y. Cui, X. Duan, J. Hu, and C. M. Lieber, "Doping and electrical transport in silicon nanowires," Journal of Physical Chemistry B, vol. 104, no. 22, pp. 5215-5216, 2000.

[15] D. D. D. Ma, C. S. Lee, and S. T. Lee, "Scanning tunneling microscopic study of boron-doped silicon nanowires," Applied Physics Letters, vol. 79, no. 15, pp. 2468-2470, 2001.

[16] K. Byon, D. Tham, J. E. Fischer, and A. T. Johnson, "Synthesis and postgrowth doping of silicon nanowires," Applied Physics Letters, vol. 87, no. 19, Article ID 193104, pp. 1-3, 2005.

[17] A. Colli, A. Fasoli, C. Ronning, S. Pisana, S. Piscanec, and A. C. Ferrari, "Ion beam doping of silicon nanowires," Nano Letters, vol. 8, no. 8, pp. 2188-2193, 2008.

[18] S. Ossicini, E. Degoli, F. Iori et al., "Simultaneously B- and Pdoped silicon nanoclusters: formation energies and electronic properties," Applied Physics Letters, vol. 87, no. 17, Article ID 173120, pp. 1-3, 2005.

[19] F. Iori, E. Degoli, E. Luppi et al., "Doping in silicon nanocrystals: an ab initio study of the structural, electronic and optical properties," Journal of Luminescence, vol. 121, no. 2, pp. 335339,2006

[20] A. K. Singh, V. Kumar, R. Note, and Y. Kawazoe, "Effects of morphology and doping on the electronic and structural properties of hydrogenated silicon nanowires," Nano Letters, vol. 6, no. 5, pp. 920-925, 2006.

[21] H. Peelaers, B. Partoens, and F. M. Peeters, "Formation and segregation energies of B and P doped and BP codoped silicon nanowires," Nano Letters, vol. 6, no. 12, pp. 2781-2784, 2006.

[22] S. Ossicini, E. Degoli, F. Iori et al., "Doping in silicon nanocrystals," Surface Science, vol. 601, no. 13, pp. 2724-2729, 2007.
[23] X. Chen, X. Pi, and D. Yang, "Critical role of dopant location for P-doped Si nanocrystals," Journal of Physical Chemistry C, vol. 115, no. 3, pp. 661-666, 2011.

[24] J. F. Ziegler, J. P. Biersack, and U. Littmark, The Stopping and Range of Ions in Solids, Pergamon Press, New York, NY, USA, 1985.

[25] F. Iacona, C. Bongiorno, C. Spinella, S. Boninelli, and F. Priolo, "Formation and evolution of luminescent $\mathrm{Si}$ nanoclusters produced by thermal annealing of SiO," Journal of Applied Physics, vol. 95, no. 7, pp. 3723-3732, 2004.

[26] G. Franzò, M. Miritello, S. Boninelli et al., "Microstructural evolution of SiOx films and its effect on the luminescence of $\mathrm{Si}$ nanoclusters," Journal of Applied Physics, vol. 104, no. 9, Article ID 094306, 2008.

[27] L. R. Doolittle and M. O. Thompson, RUMP, Computer Graphics Service, 2002, http://www.genplot.com.

[28] G. E. Jellison, S. P. Withrow, J. W. McCamy, J. D. Budai, D. Lubben, and M. J. Godbole, "Optical functions of ionimplanted, laser-annealed heavily doped silicon," Physical Review B, vol. 52, no. 20, pp. 14607-14614, 1995.

[29] L. Ding, T. P. Chen, Y. Liu, C. Y. Ng, and S. Fung, "Optical properties of silicon nanocrystals embedded in $\mathrm{SiO}_{2}$ matrix," Physical Review B, vol. 72, no. 12, pp. 1-7, 2005.

[30] M. Mansour, A. E. Naciri, L. Johann, J. J. Grob, and M. Stchakovsky, "Dielectric function and optical transitions of silicon nanocrystals between $0.6 \mathrm{eV}$ and $6.5 \mathrm{eV}$," Physica Status Solidi A, vol. 205, no. 4, pp. 845-848, 2008.

[31] V. Privitera, W. Vandervorst, and T. Clarysse, "Spreading resistance-based technique for two-dimensional carrier profiling," Journal of the Electrochemical Society, vol. 140, no. 1, pp. 262-270, 1993.

[32] B. J. Masters and J. M. Fairfield, "Arsenic isoconcentration diffusion studies in silicon," Journal of Applied Physics, vol. 40, no. 6, pp. 2390-2394, 1969.

[33] Y. Wada and D. A. Antoniadis, "Anomalous arsenic diffusion in silicon dioxide," Journal of the Electrochemical Society, vol. 128, no. 6, pp. 1317-1320, 1981.

[34] A. Höfler, T. Feudel, N. Strecker et al., "A technology oriented model for transient diffusion and activation of boron in silicon," Journal of Applied Physics, vol. 78, no. 6, pp. 36713679, 1995.

[35] M. Uematsu, "Transient enhanced diffusion and deactivation of high-dose implanted arsenic in silicon," Japanese Journal of Applied Physics Part 1, vol. 39, no. 3 A, pp. 1006-1012, 2000.

[36] M. Barozzi, D. Giubertoni, M. Anderle, and M. Bersani, "Arsenic shallow depth profiling: accurate quantification in SiO," Applied Surface Science, vol. 231-232, pp. 632-635, 2004.

[37] R. Pinacho, M. Jaraiz, P. Castrillo, I. Martin-Bragado, J. E. Rubio, and J. Barbolla, "Modeling arsenic deactivation through arsenic-vacancy clusters using an atomistic kinetic Monte Carlo approach," Applied Physics Letters, vol. 86, no. 25, pp. 1-3, 2005.

[38] M. Ferri, S. Solmi, A. Parisini, M. Bersani, D. Giubertoni, and M. Barozzi, "Arsenic uphill diffusion during shallow junction formation," Journal of Applied Physics, vol. 99, no. 11, Article ID 113508, 2006.

[39] L. W. Wang and A. Zunger, "Dielectric constants of silicon quantum dots," Physical Review Letters, vol. 73, no. 7, pp. 1039-1042, 1994.

[40] R. Tsu, D. Babić, and L. Loriatti, "Simple model for the dielectric constant of nanoscale silicon particle," Journal of Applied Physics, vol. 82, no. 3, pp. 1327-1329, 1997. 

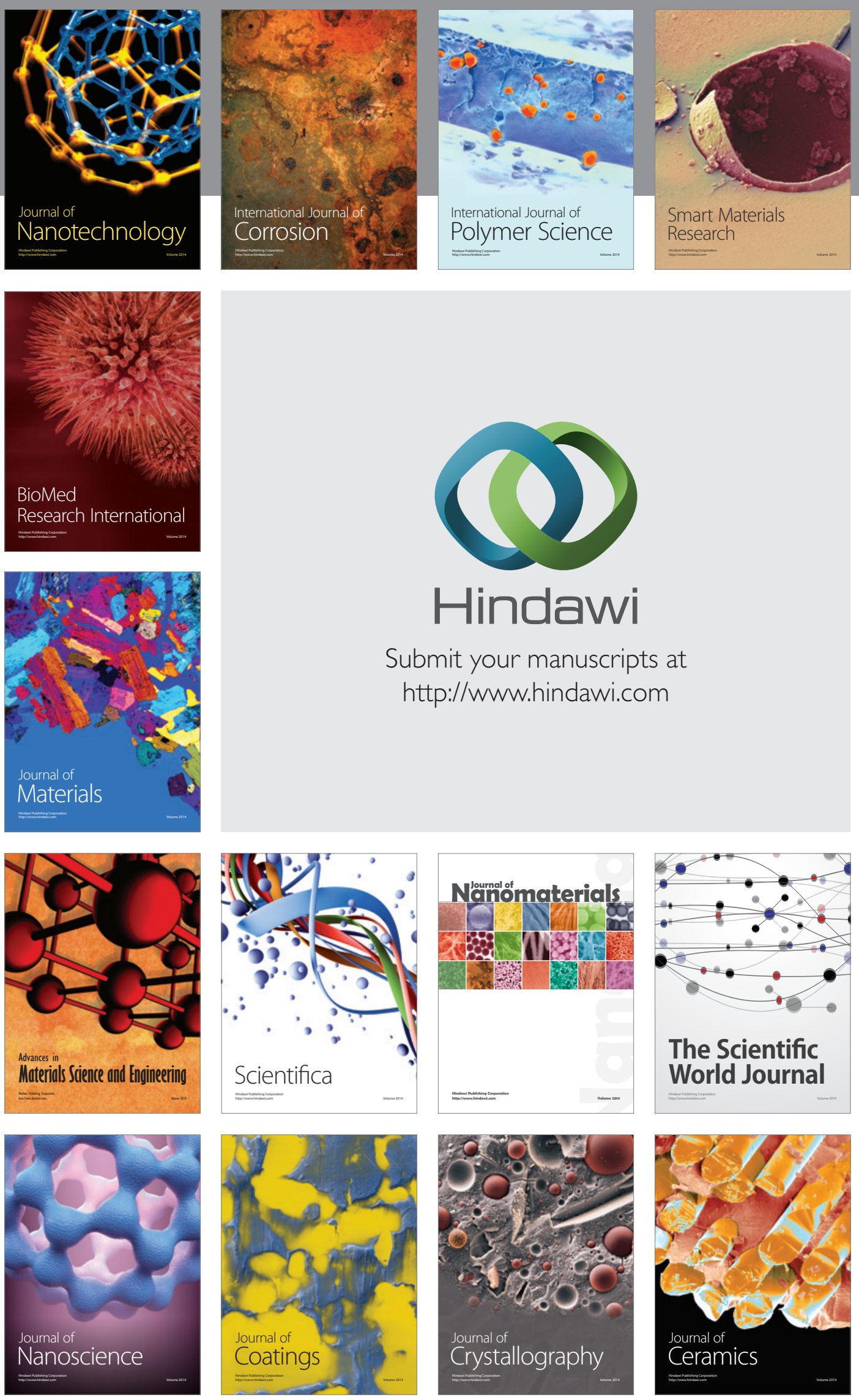

The Scientific World Journal

Submit your manuscripts at

http://www.hindawi.com

\section{World Journal}

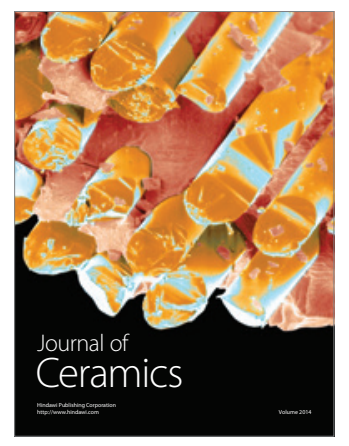

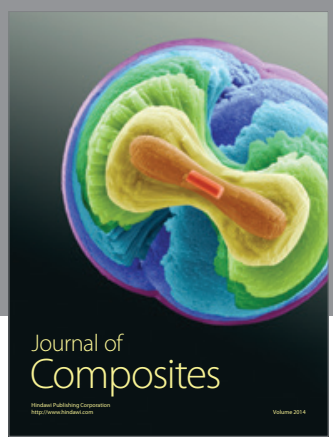
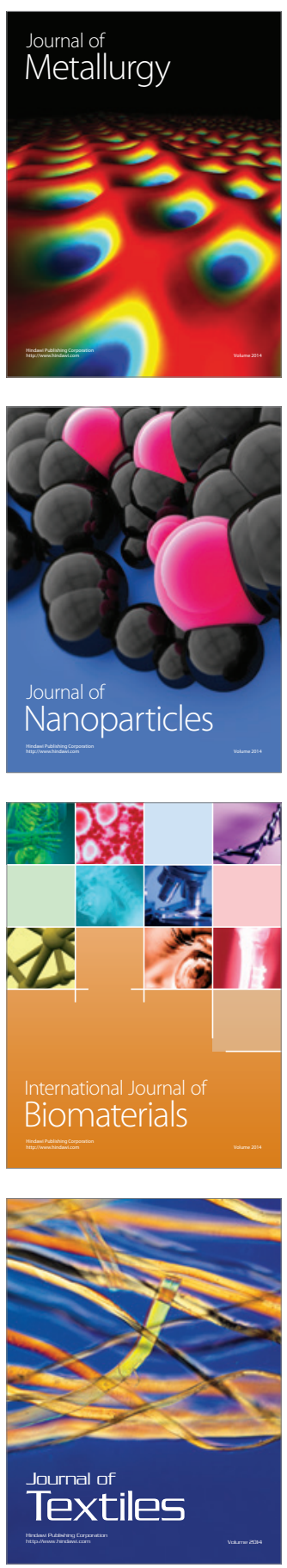